\title{
Mathematical Chance Constrained Framework Application
}

\author{
Ms. Nora Zilam Runera \\ Dean, Management Studies Department, \\ AMCRET, Russia
}

\author{
Article Info \\ Page Number: 113 - 117 \\ Publication Issue: \\ Vol 71 No. 1 (2022)
}

Article History
Article Received: 18 November
Revised: 03 December 2021
Accepted: 19 December 2021
Publication: 28 January 2022

\begin{abstract}
Chance Constrained Programming (CCP) as one of the special parts of mathematical programming in which its application in industrial and academic fields is currently needed to cover the problem of uncertainty in making decisions. The CCP technique is an efficient and easy tool to apply for data involved to random parameters by assuming random parameters must follow a stable normal distribution. In selection process, budget goal, making the most benefits, and achieving minimum travel are considered as a random parameter and solved by using CCP. Goal Programming (GP) model, will be used to model the rail system transportation project selection process, because allocating resources into all projects at the same time requires multi-criteria decision making techniques.
\end{abstract}

Keywords: - Constrained Framework, Chance Constrained Programming $(\mathrm{CCP})$ etc.

\section{Introduction}

For the transportation system data that is existing, including conveyance capacity, demand, and resource data, its precision is compromised, but exists as random, fuzzy, or both forms of data. In objective functions, therefore, there could be randomness or fuzziness, a similar observation made in the constraints. With different uncertainty forms, handling them in practical scenarios forms a critical challenge [1]. As such, optimization algorithms that focus on fuzzy and probabilistic methods have been developed, including the expected value framework, robust optimization, chance constrained programming, stochastic programming. These renowned models have been implemented in a quest to ensure that optimization-related issues are handled, especially in the wake of uncertainty. It is also notable that for uncertainties or problems such as customer demands, benefits, and costs are not replicated by linear programming, because this approach fails to incorporate multiple goals. To compensate for this deficiency, a regular integer goal programming approach entails the chance constrained capabilities [2].

For the CCP approaches that Cooper and Charnes [3] have pioneered, a deterministic problem is realized after the conversion of the stochastic formulation. In so doing, the possibility of achieving or meeting certain constraints has been exceeded. In particular, this approach achieves feasible region flexibility through the solution's confidence level variation. With an equivalent deterministic problem realized after stochastic optimization problem transformation, computational tractability is realized. Despite this outcome, it is assumed that uncertain parameters will be following stable probability distributions to achieve desired 
statistical distributions perceived to be well behaved. In this study, the central purpose lies in the presentation of a framework through which project transportation planning could be selected. The study focuses on the context of rail system projects. Indeed, given that rail systems exhibit cities' public transportation bodies, they become ideal research context. Also, with some variables normally distributed while others are random, the proposed model deemed to be ideal is that which combines the Goal Programming model, the chance constrained programming algorithm in this case. To indicate how the proposed model is developed and how it functions, a test scenario entails part of a rail system whose planning was achieved or done by Hamurcu and Eren $[4,5]$ for investments Istanbul.

\section{$2 \quad$ Methodology}

The goal programming model is established that collects different objectives under one objective for the problem. There are multiple goal in the problem such as achieving budget goal, making the most benefits, linking the most station, combining the longest distances, and achieving minimum travel time. In the mathematical model, the objective function of which deviation from the targets are minimized is defined as meeting mandatory objectives and ensuring budget constraints. Goal programming formulation as below :

Objective function :

$\operatorname{Min} Z=\left[P_{1} w_{1}\left(d_{i}^{+}, d_{i}^{-}\right)+\cdots+P_{k} w_{k}\left(d_{i}^{+}, d_{i}^{-}\right)\right]$

Constraints :

$\sum_{j=1}^{n} a_{i j} x_{j}-d_{i}^{+}+d_{i}^{-}=b_{i}$

$d_{i}^{+}, d_{i}^{-}, x_{j} \geq 0$

$i=1, \ldots, m ; j=1, \ldots, n$

$P_{i}$ : Priority, $w_{i}$ : weight, $d_{i}^{+}$: Positive deviation, $d_{i}^{-}$: Negative deviation, $a_{i j}$ : parameters vector, $x_{j}$ : decision variables.

Following the implementation of the chance-constrained programming model, there is the countering $\mathrm{f}$ or accounting for risks while determining the levels of probability $p_{i}$, especially due to the need for the satisfaction of the demand goals. An example is that in which firms could establish probability levels where production minimization can be achieved relative to demand excess and satisfaction. The eventuality is that during model implementation, there is a need for constraints to achieve a desired probability level. Also, the confidence level becomes a representation of the firm's operating system. Indeed, there can also be a CCP conversion to achieve deterministic equivalents, especially in situations involving a normal distribution of stochastic variables. The eventuality is that with more flexibilities realized, there is a possibility of considering uncertainty reliability. For the case of CCP implementation, the central assumption is that coefficients tend to abide by normal distributions, which exhibit known variances and means (Wang, 2016). The model is considered as follows:

$\operatorname{Maximize} F(X)=\sum_{j=1}^{n} c_{j} x_{j}$ 
Subject to

$\operatorname{Pr}\left[\sum_{j=1}^{n} a_{i j} X_{j} \leq b_{i}\right] \geq p_{i}$ for $i=1,2, \ldots, m$

$X_{j} \geq 0$ for $j=1,2, \ldots, n$

where $c_{j}, a_{i j}$, and $b_{i}$ are normal random variables and $p_{i}$ 's are prespecified probabilities.

Prior to the GP model formulation, there is a need for the collection of the right-hand side value and real-world coefficient data in terms of the amount of resource available and the amount of resource consumed by an attribute respectively. The next step entails the determination of the respective goals' priority levels. In turn, there is the formulation of constraints such as AHP, resource, and system priority. For the case of system constraints, deviation variables are absent. As such, equality signs are not used. Rather, inequality signs are employed. It is also from the resource constraint that a random variable could be obtained, with uncertainties appearing in the form of excess production capacity and future demand, as well as the effort to maintain the budget as originally intended. Through these variables, therefore, it can be seen that CCP is implemented to compensate for deficiency. Hence, this arrangement differentiates resource constraints from system constraints. However, based on (4), and (5), random variables are seen to exist in the form of three coefficients and this outcome attracts a state of extreme stochasticity.

Notably, there is a general consideration of $b_{i}$ 's and/or $a_{i j}$ 's and/or $c_{i j}$ 's as random attributes. Considering only independently and normally distributed coefficients, three basic cases are as follows:

1. When only $b_{i}$ 's are random : Let $e_{i}$ (nonnegative) represent a standard normal variate at which $\theta\left(e_{i}\right)=1-$ $\varphi_{i}$. Then (4) remains the same and each constraint of type (5) takes the deterministic form of (7). No nonlinear terms result in this case :

$\sum_{j=1}^{n} a_{i j} x_{j}-\bar{b}_{i}-e_{i}\left[\operatorname{Var}\left(b_{i}\right)\right]^{\frac{1}{2}} \leq 0, \quad$ for $i=1,2, \ldots, m$

2. When only $a_{i j}$ 's are random : (4) still remain the same, but constraints (5) now become nonlinear as shown below :

$\sum_{j=1}^{n} \bar{a}_{i j} X_{j}+e_{i}\left[\sum_{j=1}^{n} \operatorname{Var}\left(a_{i j}\right) x_{j}^{2}\right]^{1 / 2}-b_{i} \leq 0$ for $i=1,2, \ldots, m$

3. When only $c_{i j}$ 's are random : (5) will be unchanged. However, (4) as the objective function will end up being nonlinear. Thus,

$F(X)=k_{1} \sum_{j=1}^{n} c_{j} x_{j}+k_{2}\left[\sum_{j=1}^{n} \operatorname{Var}\left(a_{i j}\right) x_{j}^{2}\right]^{1 / 2}$

$k_{1}$ and $k_{2}$ represent coefficients that are non-negative and depict the criticality of variance and mean minimization. Should there be randomness in the three coefficients, the eventuality is that the objective function is retained, just as (9). In so doing, the form that the respective constraints (5) take becomes:

$$
\bar{h}_{i}+e_{i}\left[\operatorname{Var}\left(h_{i}\right)\right]^{1 / 2} \leq 0
$$

For $i=1,2, \ldots, m$ where $\bar{h}_{i}=\sum_{j=1}^{n} \bar{a}_{i j} x_{j}-\bar{b}_{i}$ for all $i$.

\section{$3 \quad$ Results and Discussion}

In this study, 0-1 Integer goal programming methods with Istanbul Metropolitan using an application was made for the selection of Transportation Projects in the Municipality. A lot of investment is made public transportation to reduce this density. Most of these investmens are in invesments in rail system, which are safe, comfortable, and fast transport systems. With its short, medium, and long term plans, istanbul is 
making and planning big investments in rail systems. It is aimed to reach to many points of the city by rail system such as Metro, Tramway and Monorail lines. Alternative Projects are shown in table 1.

\begin{tabular}{|c|c|c|c|c|c|c|}
\hline $\begin{array}{l}\text { Rail System } \\
\text { Type }\end{array}$ & $\begin{array}{l}\text { Name of } \\
\text { Line }\end{array}$ & $\begin{array}{l}\text { Station } \\
\text { Number }\end{array}$ & $\begin{array}{l}\text { Distance } \\
(\mathrm{km})\end{array}$ & $\begin{array}{c}\text { Travel } \\
\text { Time }(\mathrm{dk})\end{array}$ & $\begin{array}{c}\text { Approximate } \\
\text { Cost (Million \$) }\end{array}$ & Benefit ( Million) \\
\hline Metro & M1 & 12 & 14,30 & 22 & 810,00 & 88,00 \\
\hline Metro & M2 & 4 & 14,30 & 22 & 808,00 & 622,00 \\
\hline Metro & M3 & 12 & 13,00 & 19,5 & 710,00 & 1021,00 \\
\hline Metro & M4 & 5 & 6,20 & 10 & 320,00 & 99,00 \\
\hline Metro & M5 & 10 & 9,70 & 15 & 450,00 & 97,00 \\
\hline Metro & M6 & 7 & 7,60 & 12 & 380,00 & 444,00 \\
\hline Metro & M7 & 2 & 4,10 & 6 & 240,00 & 63,00 \\
\hline Metro & M8 & 6 & 6,90 & 10,5 & 350,00 & 403,00 \\
\hline Metro & M9 & 11 & 13,00 & 19,5 & 720,00 & 82,00 \\
\hline Metro & M10 & 10 & 16,24 & 25 & 980,00 & 51,00 \\
\hline Metro & M11 & 11 & 14,00 & 21 & 942,00 & 87,00 \\
\hline Metro & M12 & 11 & 18,00 & 27 & 1085,00 & 622,00 \\
\hline Metro & M13 & 4 & 5,50 & 8,5 & 350,00 & 403,00 \\
\hline Metro & M14 & 13 & 28,00 & 42 & 1420,00 & 444,00 \\
\hline Metro & M15 & 14 & 55,50 & 166,5 & 3025,00 & 742,00 \\
\hline Metro & M16 & 5 & 9,70 & 14,5 & 1030,00 & 68,00 \\
\hline Metro & M17 & 5 & 5,50 & 8,5 & 341,00 & 267,00 \\
\hline Monorail & $\mathrm{H} 1$ & 17 & 17,00 & 40 & 240,00 & 92,00 \\
\hline Monorail & $\mathrm{H} 2$ & 9 & 7,25 & 12,5 & 175,00 & 587,00 \\
\hline Tramway & $\mathrm{T} 1$ & 14 & 10,10 & 30 & 888,00 & 150,00 \\
\hline Tramway & $\mathrm{T} 2$ & 6 & 3,00 & 9 & 202,00 & 120,00 \\
\hline
\end{tabular}

Relevant data, such as that which touches on the right-hand side value and coefficients, comes in the form of 21 decision variable types, including:

$$
M_{i}=\text { Selected Metro } \operatorname{project}(i=1,2, \ldots, 17)
$$




$$
\begin{aligned}
& H_{i}=\text { Selected Monorail } \operatorname{project}(i=1,2) \\
& T_{i}=\text { Selected Tramway } \operatorname{project}(i=1,2) \\
& M_{i}\left(H_{i}\right)\left(T_{i}\right)=\left\{\begin{array}{c}
1, \text { if } \operatorname{project~selected~} \\
0, \text { otherwise }
\end{array}\right. \\
& d_{j}^{+}=\text {positive deviation } j \\
& d_{j}^{-}=\text {negative deviation } j
\end{aligned}
$$

\section{Conclusion}

This study established a stochastic programming model under uncertain constraints in railed system projects in Istanbul. Subsequently, the best projects were selected to improve urban transport among the planned transportation projects with the mathematical model established at the point of achieving the specified objectives. Urban transportation planning is one of the most difficult decision-making processes of transportation planning. The selected framework strives to offer critical data insights for the investments in transportation planning, especially in relation to variations in uncertainties and goals regarding the future demand, as well as the need to account for the same. To handle future demand's uncertainty, the implementation of chance-constrained programming is found to be logical and consistent.

\section{References}

[1] Aouni, B., Ben Abdelaziz, F., Martel, J.M., 2005. Decision-maker_s preferences modeling in the stochastic goal programming. European Journal of Operational Research 162, 610-618.

[2] Abastante, F., Lami, I.M., 2012. A complex Analytic Network Process (ANP) Networkfor Analyzing Corridor24 Alternative Development Strategies, In: 2nd International Conference on Communications Computing and Control Applications, CCCA 2012, 6-8 December, Marseilles.

[3] Banai, R.,. 2006. Public Transportation Decision-making: A Case Analysis of theMemphis Light Rail Corridor and Route Selection with Analytic Hierarchy Process, Journal of Public Transportation, 9(2), 1-24.

[4] Bhattacharya U.K. 2009. "A chance constraint goal programming model for the advertising planning problem". European Journal of Operation Research 192. P.321-295.

[5] Biswas A. and Modak N. 2013. On solving chance constrained programming problems involving uniform distribution with fuzzy parameters. Inteligent Decision Technologies 7. 151-159.

[6] Degadwala, D. S. ., \& Vyas, D. . (2021). Data Mining Approch for Amino Acid Sequence Classification . International Journal of New Practices in Management and Engineering, 10(04), 01-08. https://doi.org/10.17762/ijnpme.v10i04.124

[7] Yadav, S. ., S. . Ali, and A. . Arora. "Design Simulation of Improved Power Quality Conditioner System for Enhancement of Power Quality". International Journal on Recent and Innovation Trends in Computing and Communication, vol. 9, no. 12, Dec. 2021, pp. 19-26, doi:10.17762/ijritcc.v9i12.5496. 